no problem in the bulk of the cosmic rays being of galactic origin. Later in a more detailed analysis of the situation V. S. Berezinsky (Moscow) maintained the Soviet line by suggesting a theory that could fit the total experimental data. According to his 'naive theory', at energies below $10^{19} \mathrm{eV}$ cosmic rays are mostly protons of galactic origin. The phase of anisotropy varies with energy due to a focusing effect of the galactic magnetic fields. At higher energies an origin transition occurs with the cosmic rays reaching the Solar System largely coming from the local supercluster of galaxies with a maximum from the Virgo direction. For the moment this theory of the origin of cosmic ray particles seems to be the best compromise.

\section{Do populations regulate themselves?}

\author{
by Mary Lindley
}

A symposium on Population Control by Social Behaviour was held at the Institute of Biology in London on 20-21 September, 1977. It was organised by D. M. Stoddart (King's College, London) and F. J. Ebling (University of Sheffield), and the proceedings will be published by the Institute of Biology.

TWEnty years ago V. C. WynneEdwards propounded a hypothesis to explain why populations of animals do not expand unchecked until stopped by the exhaustion of food resources. Many and perhaps most animals, he suggested, must regulate their population densities before this stage is reached, and they do that through social competition. His work on the red grouse (Lagopus lagopus scoticus), which was carried out at the University of Aberdeen and which he recalled at the symposium, proved him correct as far as that species was concerned. Each autumn young males take up territories in a contest with established males, and the many unsuccessful birds are cast out and usually die within six months. Thus population density is regulated.

One of the purposes of the symposium was to examine how much more evidence has emerged in favour of the hypothesis. Some of the eleven speakers addressed that theme more directly than others.

Reviewing 30 years of field work

Mary Lindley is Assistant Editor of Nature. with great tits (Parus major) in Oxford and Holland, J. R. Krebs (University of Oxford) said that the birds' behaviour seems to affect population size during three stages of the annual cycle. First, during the spring breeding season the number of eggs laid by each bird can fluctuate considerably, with fewer produced when the population density is high than when it is low. This fluctuation does nat seem to be a direct consequence of changes in the amount of food available. The immediate influence is more likely to be a behavioural mechanism. Second, the survival of young birds in the summer and early autumn is an important influence on the size of the population, and aggressive interactions are at least in part the cause, with heavier birds most likely to survive. The third period when behaviour seems to be regulating population is early spring, when birds compete for territories, and exclude those that are unsuccessful. But Krebs stressed that little is known about the environmental resources to which the regulating behaviour is geared.

Indications of similar regulatory influences on populations of the woodmouse (Apodemus sylvaticus) have emerged from equally long term studies carried out in the United Kingdom and elsewhere in Europe. J. R. Flowerdew (University of Cambridge) described how from winter to winter the number of woodmice within a population remains relatively stable. From summer to summer, however, there is considerable variation and the population is smaller in summer than in winter. The size of the winter population seems to be regulated by a density-dependent process initiated in summer. Social behaviour seems to be a pant of that process, involving, for example, aggression towards immigrants and dispersal of juveniles. But more information is needed about the nature of the behaviour and about the influence of other factors, especially genetics, predation and starvation.

In primatology, however, positive conclusions seem even further away. Although primates might seem to be ideal mammals for the study of social behaviour and population structure, most of them live too long. A. Jolly (University of Sussex) pointed out that there has been pathetically little longterm fieldwork with primates. Hope is offered, however, by the lemurs of Madagascar which have a relatively short life cycle. Since 1963 sixteen studies have been carried out in the favourable circumstances of the Barenty Reserve, and although the objectives have been different in each case, the data can be combined to represent a long-term study of the sifaka (Propithecus verrauxi) and Lemur catta. A picture is emerging of stable populations, with $P$. verrauxi maintaining the same territories throughout the year and from year to year, while $L$. catta fluctuates in its use of the environment. This seems to be an ideal situation for critical study of social behaviour and population regulation. And that was as far as Jolly was prepared to go.

Her fellow primatologist J. Deag (University of Edinburgh) seemed to offer even less hope. He launched an attack on primatologists, including himself, for the way they have generally discussed the adaptive significance of social behaviour. He criticised the approach of inductive reasoning, whereby hypotheses are developed to explain behaviour on the assumption that it is adaptive. This had led to much speculation, with in many cases alternative hypotheses which are difficulit or impossible to test. Deag called for a more critical approach based on established facts and involving more rigorous testing of the predictions of hypotheses.

There is growing evidence that odours are involved in many interrelationships between behaviour and population processes in mammals. Reviewing what is known so far, D. M. Stoddart (King's College, London), explained that data on the role of odours in reproduction are hard to interpret because all were obtained in the laboratory, which is very different from the field. But three aspects of population ecology provide a function for odout. First, social dominance can be marked by odour in several species, including rabbits and marmosets. The emerging picture is of a rise in social dominance associated with increased production of scent, increased marking behaviour and a change in the composition of the odorous secretions. Second, odour can be used to mark out and maintain territory. It chiefly deters intruders and serves as a landmark by which the occupier recognises its own territory. Third, odour seems to be involved in the transmission of danger and warning signals, although so far the evidence is not strong. As Staddart pointed out, the role of odour in population regulation is another underdeveloped area of investigation.

By the end of the symposium the only conclusion to have emerged was the familiar plea that more work needs to be done. Wynne-Edwards professed himself completely content that discussion about his hypothesis is still alive. As he said, you cannot expect answers of the sont given at meetings of the British Association in Victorian times. 